\title{
Covid-19 Pandemic-Diet During Covid Pandemic
}

\author{
Shalini H. Moon and Manjusha Mahakarkar \\ Obstetrics and Gynecological Nursing Department, SRMMCON, DMIMS (Deemed to be University), \\ Sawangi (Meghe), Wardha, Maharashtra, India \\ Corresponding author email:moonshalini@gmail.com
}

\begin{abstract}
The entire world faces COVID-19 outbreak in the year 2019 and 2020. Corona viruses are a large family of viruses that exist in many different species of animals including camels, bovine animals, and bats. The new strain of corona virus identified as the cause of outbreaks of respiratory disease in people first detected in Wuhan, China, was COVID-19. WHO has published a new guide on how to eat healthily during the COVID-19 COVID pandemic and self-quarantine. The guideline contains valuable information about nutrition to help keep the immune system strong. It also has tips for a diet that supports good health while many of us are advised to stay at home and may have less opportunity to consume fresh foods and be physically active The FDA continues important research to protect public health during the COVID-19 pandemic along with other federal, state, and local agencies and public health officials around the country.
\end{abstract}

KEY WORDS: COVID-19, CDC, FDA, MERS-COV, SARS-COV AND UNICEF.

\section{INTRODUCTION}

Coronavirus is an ailing infection. Coronavirus disease (COVID-19) is a newly discovered coronavirus-caused infectious disease. Most people infected with the COVID19 virus will experience mild to moderate respiratory disease and recover without any special treatment being required. Older people and those with underlying medical conditions such as cardiovascular disease, diabetes, chronic respiratory disease and cancer are more likely to develop serious diseases 1 .

\section{Spread of corona disease:}

- The coronavirus is thought to primarily spread from person to person. This can happen between people in close contact with each other. Via droplets formed when an infected person coughs or sneezes may land in the mouths or nose of people nearby, or may be inhaled into their lungs.

- A person infected with coronavirus - even one with no symptoms - may emit aerosols when they talk or breathe. Aerosols are infectious viral particles that

Biosc Biotech Res Comm P-ISSN: 0974-6455 E-ISSN: 2321-4007

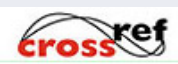

Identifiers and Pagination

Year: 2021 Vol: 14 No (9) Special Issue

Pages: 06-10

This is an open access article under Creative

Commons License Attribn 4.0 Intl (CC-BY).

DOI: $h t t p: / / d x$.doi.org/10.21786/bbrc/14.9.2 can float or drift around in the air for up to three hours. Another person can breathe in these aerosols and become infected with the coronavirus. This is why everyone should cover their nose and mouth when they go out in public.

- Coronavirus can also spread from contact with infected surfaces or objects. For example, a person can get COVID-19 by touching a surface or object that has the virus on it and then touching their own mouth, nose, or possibly their eyes.

Clinical features: Reported diseases for confirmed coronavirus disease 2019 (COVID-19) cases ranged from mild symptoms to severe illness and death. Such symptoms will show up 2-14 days after exposure (based on MERS-CoV virus incubation period).

- Fever (fever above $37.8^{\circ} \mathrm{C}$ or skin that feels hot to touch).

- Fresh, recurrent cough.

- Breathlessness and trouble breathing.

- Tired.

- Chiefs/Headache.

Hospitalization: If anybody develops emergency warning signs for COVID-19 they get immediate medical attention.

\section{The included emergency warning signs are:}

- Respiratory trouble

- Lasting chest pain or pressure 
- New confusion or disarray

- Bluish eyes or lips

Figure 1: Symptoms of coronavirus covid -19 source:

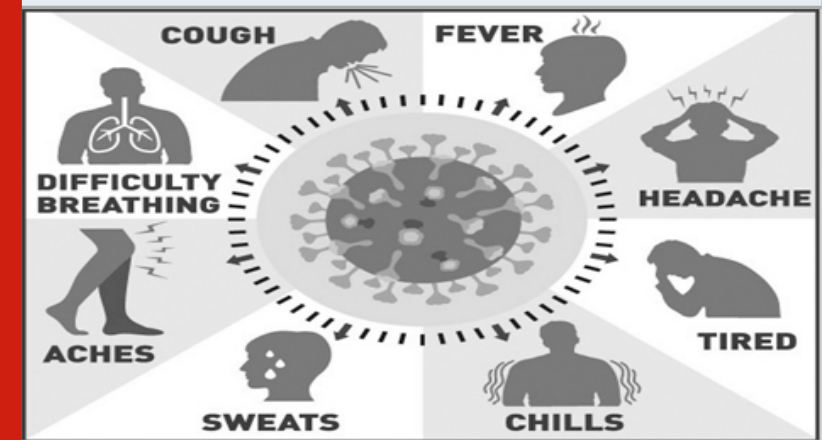

Figure 2: Ways of prevention from COVID-19 (Coronavirus)

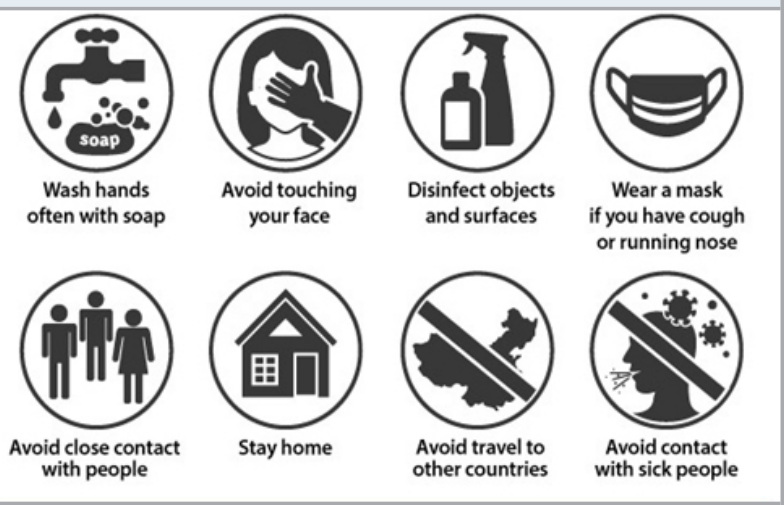

Treatment: There are currently no therapies or vaccines approved by Food and Drug Administration for COVID19 infection. Treatment provide as per Symptoms and severity of disease condition.

- Trouble breathing

- Pain or pressure in chest

- Confusion or severe drowsiness

- A blue tint to lips or face

Table 1. Food types with food Items

\begin{tabular}{|l|c|c|}
\hline Sr. No & Food Types & Food Items \\
\hline 1. & Fruits & Seasonal \\
\hline 2. & Vegetables, legumes & Boobs, lentils \\
\hline 3. & Total grain and nuts & $\begin{array}{c}\text { Maize, millet, oats, wheat, } \\
\text { brown rice or starchy } \\
\text { tuber or roots such as } \\
\text { cabbage, yams, } \\
\text { taro or cassava }\end{array}$ \\
\hline 4. & $\begin{array}{c}\text { Flesh originates from } \\
\text { animal sources }\end{array}$ & $\begin{array}{c}\text { Meags and milk } \\
\text { egrimal }\end{array}$ \\
\hline
\end{tabular}

Treatment during Hospitalization:

- Check the levels of oxygen in blood with a clip-on finger monitor
- $\quad$ Check lungs function

- Give a COVID-19 test. This involves putting a 6-inch cotton swab up both sides of the nose for about 15 seconds.

- Perform chest X-ray or CT scan

\section{Medications:}

Painkillers: To relieve pain and fever eg. Paracetamol. Antibiotics:

- Bamlanivimab- monoclonal antibody therapy

- Casirivimab and Imdevimab

Prevention: It also recommends routine preventive measures to help prevent the spread of this and other respiratory viruses, including:

- Wash your hands regularly with soap and water for at least 20 seconds, particularly after going to the bathroom; before eating; and after blowing your nose, coughing or sneezing.

- If soap and water are not readily available, use an alcohol-based hand sanitizer with at least 60 percent alcohol. Where hands are clearly dirty, always wash hands with soap and water.

- Stop to rub your eyes, nose, and mouth unwashed with your hands.

- Avoid direct contact with people who are sick.

- Stay home when you're sick and keep children when they're away from school.

- Using cough or sneeze to cover the tissue, and then dump the tissue in the garbage.

- Clean and disinfect products often treated.

The COVID-19 outbreak- Nutrition advice for adults: Everyone needs good nutrition and hydration and the two are vital. Those who eat a well-balanced diet tend to be safer with better immune systems and less chance of developing chronic diseases and infectious diseases. Start eating unprocessed and nutritious food every day Need to eat.

\section{Nutrition and health tips during self-quarantine:} General Tips:

- $\quad$ Make a plan - take only need based food items

- Be strategic about the use of ingredients - prioritize fresh products

- Prepare home-cooked meals

- Take advantage of food delivery options

- Be aware of portion sizes

- Follow safe food handling practices: Food safety is a prerequisite for healthy diets and food security. Good food hygiene guidelines include:

Tips for Food hygiene during outbreak of corona virus disease (COVID-19):

The tips for General food hygiene are:

Before cooking any meal, we need to thoroughly wash our hands with soap and water for at least 20 seconds before eating and make sure that children do the same.

- When preparing uncooked meat and fish, separate chopping boards must be used

- For cooking food recommended temperature need to be use. 
- Maintain food at safe temperatures below $5^{\circ} \mathrm{C}$ or over $60^{\circ} \mathrm{C}$

- Use clean water and raw materials.

- Keep the products cooled or frozen and pay attention to the expiry dates of the product, where possible, and keep the freezer clean.

- Recycle or dispose properly of food waste and packaging in an adequate and sanitary manner, avoiding the build-up of pest-attracting refuse.

- Always keep clean the kitchen, utensils, dishes and hands.

- $\quad$ Separate raw and cooked food, especially fresh and raw meat

- $\quad$ Meat - thoroughly cook.

Table 2. Diet Chart: Daily every person need take

\begin{tabular}{|c|c|c|}
\hline Sr. No & Food Types/Items & Quantity \\
\hline 1. & Veggies & 2.5 (5 portions) \\
\hline 2. & Outfits(Fruits) & 2 cups (4 servings) \\
\hline 3. & Grains & $180 \mathrm{gm}$ \\
\hline 4. & $\begin{array}{l}\text { Meat and beans: } \\
\text { - Red meat } \\
\text { - Poultry }\end{array}$ & $\begin{array}{l}\text { - } 1 \text { to } 2 \text { days a week } \\
\text { - Twice a week }\end{array}$ \\
\hline 5. & & Snacks: \\
\hline 6. & Fresh fruit & $2-3$ cups \\
\hline 7. & Raw vegetables, instead of food & Evite High sugar, fat, or salt. 2 Pockets \\
\hline 8. & $\begin{array}{l}\text { If eat canned or dried vegetables } \\
\text { and fruits }\end{array}$ & $\begin{array}{l}\text { Pick varieties that do not have salt or sugar added. } \\
\qquad 2 \text { Pockets }\end{array}$ \\
\hline
\end{tabular}

Note: Don’t overcook fruits and vegetables because of the loss of important vitamins.

Table 3. Adult diet guidance during covid -19 pandemic

\begin{tabular}{|c|c|c|}
\hline Sr. No. & $\begin{array}{c}\text { Nutrition } \\
\text { advice }\end{array}$ & Plan \\
\hline 1. & $\begin{array}{l}\text { Enough water } \\
\text { for drinking } \\
\text { every day }\end{array}$ & $\begin{array}{l}\text { - Water brings nutrients and compounds into the blood } \\
\text { - Water is vital to life and is very important. } \\
\text { - Drink } 8-10 \text { cups of water every day. } \\
\text { - It regulates a person's body temperature, reduces waste, lubricates and cushions the joints }\end{array}$ \\
\hline 2. & $\begin{array}{l}\text { Fat and oil -eat } \\
\text { moderate } \\
\text { amounts. }\end{array}$ & $\begin{array}{l}\text { - White meat and fish (e.g., poultry), } \\
\text { - Usually low in red meat and not fat. } \\
\text { - Evite trans processed meat and meat produced industrially. } \\
\text { - Eonsume low-fat or low-fat forms of milk and dairy products. } \\
\text { - Eat unsaturated fats and not saturated fats }\end{array}$ \\
\hline 3. & $\begin{array}{c}\text { Eat low sugar } \\
\text { and salt }\end{array}$ & $\begin{array}{l}\text { - Limit the salt and high-sodium condiments in cooking and food preparation. } \\
\text { - Restrict daily salt consumption to less than } 5 \mathrm{~g} \text { (about } 1 \text { teaspoon), and use iodized salt } \\
\text { Pick fresh fruit instead of sweet treats such as cookies, cakes and chocolate. } \\
\text { - Avoid products rich in salt and sugar } \\
\text { - The consumption of soft drinks or sodas and other high in sugar beverages should be } \\
\text { limited }\end{array}$ \\
\hline 4. & $\begin{array}{l}\text { Eat Homemade } \\
\text { foods }\end{array}$ & - Avoid eating outside; eat only homemade foods to avoid COVID-19 exposure. \\
\hline 5. & $\begin{array}{l}\text { Psychosocial } \\
\text { assistance and } \\
\text { therapy }\end{array}$ & $\begin{array}{l}\text { - Magic bullets are healthy nutrition and hydration for wellbeing and immune system } \\
\text { changes. } \\
\text { - To keep the population in good health. } \\
\text { - Get specialist advice and psychosocial assistance. }\end{array}$ \\
\hline
\end{tabular}

- $\quad$ Limit salt intake: The WHO recommends eating less than $5 \mathrm{~g}$ of salt a day. To do so, priority should be given to foods with reduced or no added salt.

- Limit sugar intake : WHO recommends that ideally less than 5\% of total energy intake for adults should come from free sugars (about 6 teaspoons). Limit the amount of sugar or honey added to foods and avoid sweetening our beverages.

- Limit fat intake: Limiting the total intake of fat to less than 30 percent of the total intake of oil, which no more than 10\% should come from saturated fat. To achieve this, opt for cooking methods that require less or no fat, such as steaming, grilling or sautéing instead of frying foods.

- $\quad$ Consume enough fibre: Fiber contributes to a healthy digestive system and provides a prolonged sense of fullness which helps prevent excessive eating. To ensure an sufficient intake of fibre, all meals will contain vegetables, fruit, pulses and wholegrain foods. Wholegrain products include peas, brown pasta and rice, bread and wraps of quinoa and whole wheat rather than refined grain foods, such as white pasta and rice, and white bread.

- Stay hydrated

- Avoid alcohol or at least reduce alcohol consumption

- $\quad$ Enjoy family meals

- According to UNICEF guideline: The healthy eating tips are; 
Figure 3: Prioritized Food Hygiene Behaviors

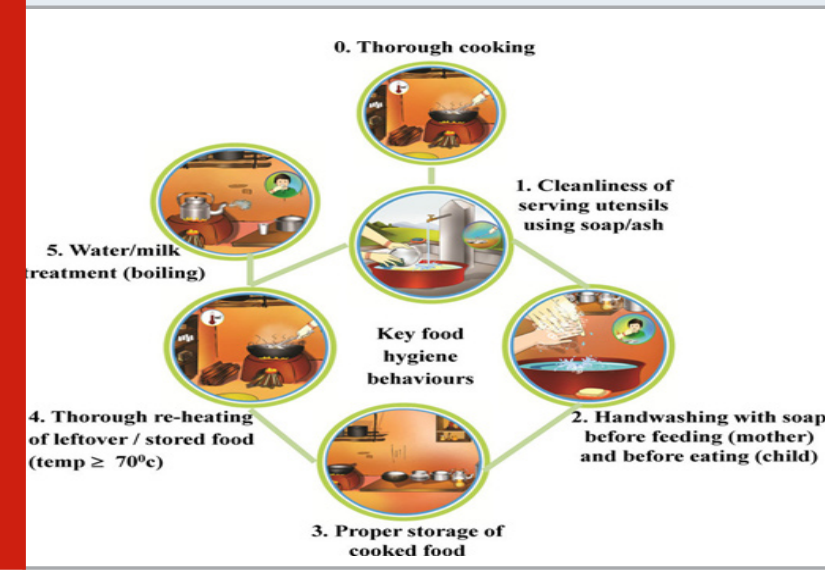

1. Take fruit and vegetable

2. When fresh produce is not available swap in healthy dried or canned alternatives

3. Keep stock of healthy snacks

4. Reduce intake of highly processed foods

5. Make cooking and eating a fun with family

Breastfeeding Advice for Children: Between 6-24 months breast milk remains a great food for children. Women with COVID-19 are permitted to continue breastfeeding if they wish to. If mother with COVID-19 separates mother and newborn baby and starts feeding artificially or if human milk bank is available also give that milk or use the options available. Breast milk provides babies with the best source of nutrition and protects them from disease. Breastfeeding disruption can lead to a drop in milk supply, the infant's refusal to take the breast and a decrease in protective immune factors in breast milk.

\section{According To Unicef Guideline:}

I. Continue breastfeeding while keeping hygiene in mind: The virus was not found in breast milk and all mothers recommended that breastfeeding continue while practicing good hygiene while feeding. The $3 \mathrm{Ws}$ include in breastfeeding:

- Wear a mask while being fed,

- Wash hands with soap before and after baby has touched,

- Wipe the surfaces and disinfect them regularly.

The main risk to a baby is to catch the virus from close contact with the mother or other family member who is infected. If someone in the household is sick, take extra care in practicing the 3 Ws to protect the baby. Many mothers may opt to wear a mask as a routine during feeding to ensure their child is covered to the full. If a mom suspects she may have contracted coronavirus, she may wish to use a clean cup or cup and spoon to express her breastmilk and feed the baby.

II. Take more hygiene steps and continue to breastfeed if mother is sick: Prior to delivery, mothers who are infected with coronavirus and begin breastfeeding and those mothers who are infected during breasfeeding will produce immune factors (antibodies) in their milk to protect their baby and improve the baby's own immune responses. Which means the only way to fight the infection and protect the unborn baby is to start breastfeeding. If a mother is sick with signs of fever, cough, or breathing problems, Mother will seek medical treatment as early as possible and obey a health care provider 's instructions. Those mothers who are good enough to breastfeed their baby should continue to do so by taking additional hygienic care by practicing the 3 Ws whenever the mother goes to near her baby including wearing a mask.

III. When the mother is too ill and is unable to breastfeed, using a cup and a spoon of concentrated breast milk to feed infants: Sick lactating mother should seek immediate medical advice. If mom can still express breast milk and ask a non-infected family member to feed the newborn using cup or cup $\mathrm{Ct}$ spoon. Please remember to keep track of the 3 Ws all the time and keep the baby safe, clean and healthy.

IV. Special care While formula feeding: Breastfeeding is just the right food for healthy baby growth and development. But when the mother lactates she can't breastfeed or decides not to breastfeed her advice on formula feeding. In this condition we must feed the babies as per the packaging instructions. Every time, the 3 Ws followed.

\section{CONCLUSION}

COVID-19 coronavirus outbreaks are a community health emergency. This time period is very stressful for everyone affected. Remember it's important to stay informed and to be kind and supportive to each other. Peoples maintain our health by taking healthy nutritious diet and also follow the available, updated guideline's provided or published by the government and not to believe on fake news.

\section{REFERENCES}

Błaszczyk-B囚benek, E., Jagielski, P., Bolesławska, I., Jagielska, A., Nitsch-Osuch, A. and Kawalec, P., (2020). Nutrition behaviors in Polish adults before and during covid-19 lockdown. Nutrients, 12(10), p.3084.

Bogoch, I.I., Watts, A., Thomas-Bachli, A., Huber, C., Kraemer, M.U. and Khan, K., (2020). Pneumonia of unknown aetiology in Wuhan, China: potential for international spread via commercial air travel. Journal of travel medicine, 27(2), p.taaa008.

de Faria Coelho-Ravagnani, C., Corgosinho, F.C., Sanches, F.L.F.Z., Prado, C.M.M., Laviano, A. and Mota, J.F., 2021. Dietary recommendations during the COVID19 pandemic. Nutrition Reviews, 79(4), pp.382-393.

Elfagi, S., Nouh, F. and Omar, M., (2020). Chronic Obstructive Pulmonary Diseases Nutritional Guideline. EAS Journal of Nutrition and Food Sciences, 2, pp.5561.

Gleeson, M., (2013). Exercise, nutrition and immunity. 
In Diet, immunity and inflammation (pp. 652-685). Woodhead Publishing.

Gleeson, M., Nieman, D.C. and Pedersen, B.K., (2004). Exercise, nutrition and immune function. Journal of sports sciences, 22(1), pp.115-125.

Hobbs, M., Pearson, N., Foster, P.J. and Biddle, S.J., (2015). Sedentary behaviour and diet across the lifespan: an updated systematic review. British journal of sports medicine, 49(18), pp.1179-1188.

Mansoorian, M., Noori, R., Khosravan, S., Tabatabaeizadeh, S.A. and Khajavian, N., (2021). Nutritional knowledge, attitude and behaviours regarding Coronavirus Disease 2019 among residents of Gonabad, Iran. Public Health Nutrition, 24(5), pp.1088-1094.

Mumena, W., (2021). Impact of COVID-19 Curfew on Eating Habits, Eating Frequency, and Weight According to Food Security Status in Saudi Arabia: A Retrospective Study. Prog. Nutr, 22, p.e2020075.

Naja, F. and Hamadeh, R., (2020). Nutrition amid the COVID-19 pandemic: a multi-level framework for action. European journal of clinical nutrition, 74(8), pp.1117-1121.

Omar, M., Elfagi, S. and Nouh, F., (2020). COVID-19 and nutrition: Review of available evidence. Sch J App Med Sci, 8(4), pp.1158-64.

Prasad, R., Perappadan, B.S., Shelar, J. and Koshy, J., (2020). The Pandemic Notebook. A Handy Guide from the Hindu on Understanding the Coronavirus Pandemic and Staying Protected against COVID-19. The Hindu. Scully, M., Dixon, H. and Wakefield, M., (2009).
Association between commercial television exposure and fast-food consumption among adults. Public health nutrition, 12(1), pp.105-110.

World Health Organization, (2020). Nutrition advice for adults during the COVID-19 outbreak. World Health Organization, Regional Office for the Eastern Mediterranean.

World Health Organization, (2020). Nutrition Advice for Adults During the COVID-19 Outbreak.(2020).

World Health Organization, (2020). World Health Organization coronavirus disease 2019 (COVID-19) situation report.

Wypych, T.P., Marsland, B.J. and Ubags, N.D., (2017). The impact of diet on immunity and respiratory diseases. Annals of the American Thoracic Society, 14(Supplement 5), pp.S339-S347.

http://www.emro.who.int/nutrition/nutrition-infocus/ nutrition-advice-for-adults-during-the-covid-19outbreak.html

https://www.cdc.gov/coronavirus/2019-ncov/ symptoms-testing/symptoms.html

https://www.nccih.nih.gov/health/in-the-newscoronavirus-and-alternative-treatments

https://www.swgeneral.com/COVID-19/COVID-19Prevention.aspx

https://www.unicef.org/eap/breastfeeding-duringcovid-19

https:// w w w. who.int/health-topics / coronavirus\#tab=tab_1 